two and a half hours, with the result that the next day the eruption had returned and was as extensive as before. A week later the same result followed a similar experiment. By March 14th the spots had gone but as the jacket had to be taken off he could not be allowed to get up. He remained in hospital until March 19th when he left at his own request. The treatment, which seemed to have no effect, consisted of at first lemon juice, half-ounce doses taken in soda-water three times a day; secondly, ten-minim doses of turpentine three times a day; and lastly, 15 grains of calcium chloride in water three times a day. The effect of the last remedy is not known as the patient had to be kept in a recumbent position owing to the state of his spine.

'This is a well-marked case of orthostatic purpura, such as is commonly seen after acute rheumatism, where the eruption comes out as soon as the patient is allowed to get up and disappears when he resumes a horizontal position. It is apparently due to the state of the blood and usually passes off in a few weeks. The blood condition is not known. It might be suggested that the condition in this case was due to the lesion in the cord, the injury there setting up vaso-motor paralysis, but it seems unnecessary to adopt such a hypothesis in view of the fact that the disease often occurs in conditions where the spinal cord is quite healthy. In using the name "orthostatic purpura "it is not intended to make a fresh subdivision but merely to direct attention to this peculiarity. In 1881 it was suggested by Ceci of Prague that purpura might be caused by the action of an organism which he believed he had isolated, and which, when injected into the veins of animals, caused hæmorrhages. These statements have never been confirmed but micro-oroanisms have been found by one or two other observers. On the other hand, I have had all my cases examined systematically and the blood has in every case been found sterile. It is therefore fair to assume that organisms are not necessarily present and possibly when they have been found the result has been due to defective methods.

Birmingham.

\section{UNCOMPLICATED MYOCARDITIS IN A GIRL IN HER EIGHTH YEAR ASSO- CIATED WITH SIGNS OF CARDIAC FAILURE AND FOLLOWED BY SUDDEN DEATH. ${ }^{1}$}

BY GEORGE CARPENTER, M.D. LOND.,

PHYSICIAN TO THE EVELINA HOSPITAL FOR CHILDREN; ASSISTAN PHYSICIAN TO THE NORTH-EASTERN HOSPITAL FOR CHILDREN.

A GIRL, aged seven years and 11 months, was brought to the North-Eastern Hospital for Children on Jan. 11th, 1904. Her health had been quite good until July, 1903; at that time she had an ulcerated mouth and her breath was very offensive. Since August she had been an out-patient at the Adelaide Infirmary. She went to Sunday school on Jan. 10th but fainted while there and was carried home. There was history neither of diphtheria nor of rheumatism to be obtained. She had never had scarlet fever. When I saw her she was somewhat cyanosed. Her pulse was weak at the wrist and the first cardiac sound was not good. The second at the left base was accentuated. There was no extension of dulness to the right and there was no regurgitant pulse in the ressels of the neck. A few bronchitic signs were to be heard over the lungs and the free edge of the liver was felt two fingers' breadth below the costal margin in the nipple line. The patellar reflexes could not be obtained; the soft palate acted but not very freely. Her urine was nearly solid with albumin. I thought her to be suffering from myocarditis and admitted her into hospital. On the day of admission the highest pulse-rate was 136 to the minute and the highest respiration-rate was 48 to the minute. Nothing abnormal was detected in her fundus oculi. Her temperature was $97.8^{\circ} \mathrm{F}$. On the following day she was much worse. She was cyanosed; the breathing was shallow and irregular; the heart sounds were very faint

1 The specimens were exhibited at the Socicty for the Study of Disease in Children on Feb. 19th, 1904. and feeble and the pulse could not be felt at the wrist. She died at 3.30 P.M.

The post-mortem examination was made on the following day at 2.30 P.M. She was a well-nourished child ; rigor mortis was passing off. There were four ounces of serum in the abdominal cavity and one and a half ouncesin the pericardial sac. The heart weighed seven ounces. Its valves were healthy. The right side was slightly dilated; it was thinwalled, pale, and friable. The left ventricle was of normal thickness ; it also was very pale and friable. Both auricles were dilated and pale. The heart was pale on its endocardial surface as well as on its pericardial aspect. All its cavities were filled with blood clots. The extreme pallor of the heart was the most striking feature. The lungs were heavy and dropsical; the right weighed nine and a half ounces and the left seven and a half ounces. The liver was pale; its free edge was on a level with the costal margin in the nipple line. The right kidney weighed three and a half ounces and the left three ounces; they were pale. The spleen and pancreas were normal ; the former weighed one and a half ounces and the latter two ounces. The mucous membrane of the stomach was injected and it contained a little altered blood. The intestines were normal. The brain, which weighed $40 \frac{1}{2}$ ounces, was normal.

Mioroscopioal examination.-The heart muscle was stained by Marchi's method, which showed fatty degeneration of some of the muscle fibres of both ventricles and auricles. The straight tubules of the kidney contained a considerable number of red blood corpuscles. The corpuscles were shrivelled and old, they were widely distributed, and filled the lumen of many of the straight tubules, forming casts there. In addition the two-thirds of the kidney nearest the pelvis contained an amount of scattered pigment granules. These granules were not uniformly distributed, certain areas being quite free from them, while in other parts they were very numerous and closely aggregated. They varied in colour from golden yellow to nearly black. Some were incorporated with the cells of the tubules but others lay on their surface. In places their origin from the altered blood cells could be made out

Remarks.-In vol. iii. of the Reports of the Society for the Study of Disease in Children (pp. 170-81) and the paper which was read before the society and published in full in THE LANCET of May 30th, 1903, p. 1508, I drew attention in this country, under the heading of " Uncomplicated Myocarditis in Children," to the occasional occurrence of clinical examples of primary degeneration of the heart muscle in the young with all the symptoms of valvular disease and without endocarditis, of which the case whose history I have just narrated and from whom the specimens which I now show were taken is an excellent example. Long prior to this, in 1896, I had called attention to the condition in America. ${ }^{2}$ In my other cases, one, postdiphtheritic, whose cardiac symptoms were much like those of the child under discussion, recovered. Another of unknown causation died and interstitial myocarditis was found post mortem. A third, of rheumatic origin, died suddenly and fatty degeneration of the heart muscle was found. A fourth, a boy, aged 12 months, showed extensive fibroid disease of the heart. The child died suddenly and general tuberculosis was found at the necropsy. The cause of the heart disease was not obvious and possibly rheumatism was responsible. There was no evidence of syphilis. In the present example the cause for the fatty degeneration of the heart is not certain, but I am inclined to the view that it is post-diphtheritic; at least, that appears to me the most likely solution.

I claim for myocarditis, including in this term cases of fatty degeneration of the muscle fibres pure and simple, a distinct clinical entity. I have used the term myocarditis with intent and not because $I$ wish it to be understood that I consider there is anything about the condition of an inflammatory nature. For one reason it is customary at the present time in text-books on children's diseases to group such conditions under the heading myocarditis, but $I$ have used the term chiefly because I wish the case to appear as an addendum to my recent communication on myocarditis in children. The disorder in a pronounced case, in the absence of complaints known to produce it, can be diagnosed during life; and it is a state, dangerous though it be, from which recovery can and does take place, even in a severe case, as I have more than once observed. The incidence of cardiac symptoms in association with diphtheria, rhenmatism, or

2 Two Fatal Cases of Heart Disease in which the Cardiac Muscle was alone Involved, Pediatrics, vol. i1., pp. 234-38. 
sepsis facilitates the diagnosis. Myocarditis is likely to be overlooked in cases where the primary disorders which produce the complaint have passed unnoticed, as is very likely to happen and as a matter of fact frequently does happen, and when the patient first comes under observation as a case of heart disease, especially if the condition some. times happens to be associated with cardiac bruits independent of valvular lesions. Of cases of temporary cardiac invalidism there must be many examples which escape detection. Now that attention is drawn to the condition it is hoped that it may bring forth valuable observations in the future on an important subject which needs further and more extended investigations.

Welbeck-street, $\mathrm{W}$.

\section{A CASE OF ANILINE POISONING.}

\section{BY P. G. HARVEY, M.B. LoND., L.R.C.P. LoNd, M.R.C.S. ENG.,}

LATE HOUSE PHYSICIAN A'I' IHE WORCESTER GENERAL INFIRMARY.

A MARRIED woman, aged 27 years, was admitted into the General Infirmary, Worcester, on May 10th, 1904, under the care of Dr. Mabyn Read, with the following history. For the last two months she had suffered from a painful swelling of the lips and gums, the pain being so severe as to prevent her taking solid food. 'l'here was no increased salivation. For the last two months she had also suffered from considerable shortness of breath and a feeling of faintness. A fortnight after the onset of these symptoms she noticed a discolouration of the gums and the inner side of the cheeks. About this time she began to suffer from sickness; vomiting occurred immediately after taking food which was returned unaltered. The nature of the food taken made no difference to the sickness and there was no abdominal pain, diarrhœe, or constipation. The patient said that her urine was very dark in colour about this time. She did not remember taking any food which upset her, nor had anyone else in her house suffered from similar symptoms. Six weeks previously she came to the infirmary as an outpatient but for family reasons would not become an inpatient; she only attended twice and since then had been obliged to keep indoors and to lie down on account of the shortness of breath. She had been attended by her private medical adviser for the last six weeks. During the last week her general condition had improved and she had not had any sickness. The past history and family history were unimportant.

On admission the patient was pale but not markedly anæmic-looking. Her complexion was somewhat sallow. The breath was offensive and the tongue was coated with a brownish fur. On examining the gums the first thing to attract attention was the pigmentation which was situated at the alveolar margin ; it was dark blue in colour, being not unlike the pigmentation seen in lead poisoning but rather brighter in colour. Unlike the "line" of lead poisoning it was more like a band of pigmentation, as it extended further over the gums, in some places being fully a third of an inch deep, gradually fading into the normal colour of the gum. It was most marked on the labial aspect of the gum but was also present on the lingual aspect. It was especially noticeable around the upper left second molar which was very carious; it was also noticeable along the gum where several teeth had fallen out or had been removed some time before. On the mucous membrane of the cheeks, parallel with, and opposite to, the teeth of both the upper and lower jaw on both sides of the mouth were two bands of similar pigmentation, but the outline was much more wavy and about half an inch deep. These bands extended right round the mouth and behind on to the mucous membrane, covering the ascending ramus of the lower jaw. There was no pigmentation on the palate. All the organs were healthy. 'There was no sign of paralysis in the limbs. No increased pigmentation was found elsewhere on the body. The urine was of specific gravity 1018, acid, and contained no albumin.

A diagnosis of possible ptomaine poisoning or a local infection in the mouth from some unknown micro-organism was made. Lead poisoning was excluded by the absence of paralysis at the wrists, the presence of piomentation on the cheeks, and by the nature of the pigmentation on the gums. 'The sickness did not secm like the ordinary lead colic. Addison's discase suggested itsolf on account of the gastric symptoms from which the patient suffered, but the pigmentation was unlike that found in this disease and did not exist elsewhere. The treatment was purely symptomatic, a bismuth mixture and an antiseptic mouth wash which were used when she was an out-patient were continued, fluid food only being given. A culture from the mouth was not made at the time. One made later showed staphylococci and streptococci only.

On May 16th Dr. G. W. Crowe saw the patient and at once suggested aniline poisoning as a possible cause for her symptoms. On following up this idea it was found that she was in the habit of using an indelible pencil for writing, which she moistened in her mouth from time to time. She had used this class of pencil for years and did not think that she had used it more than usual lately. She promised to obtain the pencil but failed to do so. A similar pencil tested afterwards gave most of the tests for aniline. The urine was examined with negative results. The patient was discharged on May $28 \mathrm{th}$, the general symptoms having subsided and the pigmentation having steadily decreased, especially on the cheeks.

This case seems remarkable on account of the length of time during which the habit of sucking the pencil had existed without previously causing any symptoms. Dixon Mann ${ }^{1}$ mentions cases of aniline poisoning which resemble the above case fairly closely. When a large quantity was swallowed at one time vomiting, dizziness going on to coma, dyspncea, and intense blueness of the surface were prominent symptoms. Milder cases suffered from discolouration of the lips and face without dyspnoea and vomiting. $\mathrm{He}$ also quotes Rayner" who relates a series of cases which seem very similar. The aniline in these cases was absorbed from napkins which were marked with a stamp the ink of which was aniline. Locally the buttocks and vulva were stained. The children, who were newly born, had blue discolouration of the gums, lips, and palate; the skin was dusky but no general symptoms were noted.

I am greatly indebted to Dr. Read for permission to publish, and also for kindly revising an account of, this case. Penzance.

\section{CERVICAL FIBROID OF THE UTERUS OBSTRUCTING LABOUR; CASAREAN SECTION : SUPRAVAGINAL HYSTERECTOMY.}

By H. I. D. ACLAND, F.R.C.S. ENG.

HONORART SLRGFON, CHRISTCHURCH HOSPITAL, NEW TEALAND.

THE following case from its comparative rarity seems to me worthy of publication. The patient, aged 39 years, who had been married seven years, had reached full term of her third pregnancy. The first confinement occurred five years ago: the labour lasted seven hours and forceps were used. The second confinement took place two years and eight months previously; the labour lasted 12 hours and the child was born before the arrival of the medical attendant. After the second confinement until the third pregnancy commenced menstruation was regular and there was no increase in the amount lost at each period. In the early months of the third pregnancy there were no abnormal symptoms, but during the last six weeks she suffered discomfort and pain of a bearing-down character, so that she often thought labour was commencing. There was increased frequency of micturition and diarrhoea was present almost throughout the whole pregnancy.

Labour commenced on May 11th, 1904, at 2 A.M.; the pains were strong and regular throughout the day. Between 7 and 8 P.x. she was seen by Dr. J. Cooke of Lincoln who found on examination a large fibroid blocking the pelvis and immediately sent her to the Christchurch Hospital for operation. She was driven a distance of 12 miles in a dog. cart, kneeling on the floor of the vehicle with her arms resting on the seat, and arrived at the hospital at about 11 P.M.

On examination the abdomen presented the usual appearance seen at the end of pregnancy ; the uterine pains were so 1 Forensic Medicine and Toxicology, edition 1898, p. 561 . 